Хавлла Хошави Мухаммад

аспирант кафедры социологии

Российского университета дружбы народов

\section{ОСОБЕННОСТИ ФОРМИРОВАНИЯ ЭТНИЧЕСКОГО САМОСОЗНАНИЯ КУРДОВ ЮЖНОГО КУРДИСТАНА}

Hawlla Khoshawi Muhammad

PhD student, Social Science Department, Peoples' Friendship University of Russia

\section{Аннотация:}

В статье анализируются характерные черты формирования и укрепления этнического самосознания курдов в Южном Курдистане. Показано, как многовековое проживание на общей территории, отличающейся особым ландшафтом и географическим положением, влияет на формирование социальных отношений и специфических социальных структур. Исследуется влияние племенной структуры курдского общества на развитие этнического самосознания. Формирование этнического самосознания курдов рассматривается как этап, предшествовавший возникновению и проявлению национального сознания народа. Выявляются социальные и политические условия, позволившие Южному Курдистану стать колыбелью освободительного движения курдского народа. Установлены факторы, препятствовавшие появлению подлинного национального сознания вплоть до конца XIX - начала XX в.

Ключевые слова:

Южный Курдистан, курды, этническое самосознание, национальное сознание, социальная идентичность, групповая солидарность, племенная структура, этносоциальная консолидация.
FEATURES OF THE KURDS' ETHNIC IDENTITY FORMATION IN SOUTH KURDISTAN
Summary: the formation and consolidation of the Kurds' ethnic identity in South Kurdistan. The study shows how the centuries-long living together within the territory with distinct landscape and location can influence on the formation of social relations and specific social structures. The paper examines the impact of the tribal structure of the Kurdish society on the development of ethnic identity. The article studies the formation of the Kurds' ethnic identity as a stage prior to the emergence and manifestation of national consciousness of people. It identifies the social and political conditions that allowed the Kurds in South Kurdistan to start the liberation movement of the Kurdish people. In addition, the paper examines the factors that hinder the emergence of a genuine national consciousness until the late $X I X$ - early $X X$ centuries.

Keywords: South Kurdistan, Kurds, ethnic identity, national consciousness, social identity, group solidarity, tribal structure, ethnic and social consolidation.

Социальные процессы, протекающие сегодня на Ближнем Востоке, затрагивают весь мир. «Арабская весна», экспансия запрещенной в РФ террористической группировки ИГИЛ не просто трансформировали социальную структуру региона, но изменили мировое социально пространство. Глобализация как сложный социальный феномен все чаще сопровождается локальным усилением автономизации. Нередко автономизация основывается на поиске и усилении этнической и/или национальной идентичности. Осуществить анализ социальных преобразований в современных обществах невозможно без изучения процессов становления и укрепления этнического самосознания.

На сегодняшний день этническая идентичность - один из наиболее актуальных видов социальной идентичности. Изучение данного феномена с позиций исторических, политологических, психологических наук представляется недостаточным. В рамках социологического подхода анализ этнической идентичности опирается на изучение социально-экономических особенностей развития этнической группы. В связи с новыми вызовами интерес от исследования внутригрупповых этнических ситуаций, конфликтов переходит на большие социальные общности, механизмы влияния этнических фракторов на социальную структуру, а также социальную детерминированность этнического самосознания.

Как и другие виды социальной идентификации, этническое самосознание позволяет индивиду причислить себя к некоторой группе (мы), отличающейся от других групп (они). В рассматриваемом виде социальной идентификации ключевыми характеристиками для описания группы становятся те, что свидетельствуют об общности происхождения, единой исторической судьбе: общность территории, общность или близость языка, схожие черты материальной и духовной культуры, обычаев и нравов (последнее можно обозначить как единый менталитет). Сложившись и укрепившись в представлениях социальной группы, этническое самосознание способно сохраняться вне обозначенной для идентификации территории в условиях утраты знания родного языка и некоторых других идентификационных признаков.

Чувство принадлежности к определенной социально-этнической группе, сложившееся как следствие объективно существующих социальных связей в рамках этнической группы, рассматри- 
вается как этническое самосознание. С одной стороны, оно детерминировано социально-экономическими и историческими условиями существования этносоциальной группы, с другой стороны, этническая идентификация выступает фактором изменения социальной структуры общности.

В связи с вышеизложенным представляет интерес исследование особенностей процесса этнического самоопределения курдского народа. В статье акцентируется внимание на описании сути объективно существующих социально-экономических и исторических условий и их влиянии на этническое самоопределение курдов и укрепление групповой солидарности до появления первых курдских национальных движений и организаций [1, p. 68].

Курды по праву считаются автохтонным народом, с момента своего возникновения и до сегодняшнего дня населяющим территорию, называемую Курдистаном. Современный Курдистан территория в центре Ближневосточного региона, включающая северный Ирак (Южный Курдистан), северо-западный Иран (Восточный Курдистан), юго-восточную Турцию (Северный и Западный Курдистан), северную Сирию (Юго-Западный Курдистан). Он занимает центральную часть воображаемого четырехугольника, на северо-западе и юго-западе ограниченного Черным и Средиземным морями, а на северо-востоке и юго-востоке - Каспийским морем и Персидским заливом. На обозначенной территории курды составляют большинство населения. Во времена первых упоминаний о курдах в исторических источниках курды заселяли меньший по площади регион с историческим центром в Южном Курдистане. Естественный прирост курдского населения и богатая историческими и политическими событиями жизнь региона способствовали расширению границ Курдистана.

Первые упоминания о появлении курдского этноса на обозначенных территориях относятся к I тыс. до н. э. Предполагается, что курды - прямые потомки ираноязычных мидийских племен, заселивших описываемые территории не позднее середины I тыс. до н. э. [2, р. 22; 3, c. 189-191]. Курды - древнейший народ Западной Азии. Однако процесс этногенеза, а вместе с ним и формирование этнического самосознания отличались характерными только для курдов чертами. Причина кроется в территории расселения курдов, в центральном геостратегическом положении региона на Ближнем Востоке.

История региона сопряжена с перманентно протекавшими захватническими войнами, восстаниями и междоусобицами. К моменту первого разделения этнографического Курдистана, повлиявшего на фрормирование современных границ, фрормально - к 1639 г. [4, р. 50], а фрактически - к 1514 г. [5, р. 14], курдский народ пережил многочисленные исторические перипетии: подчинение в той или иной степени династиям, подвластным Ахеменидам (VI-IV вв. до н. э.), Аршакидам, Сасанидам, изредка сменяемым римлянами и византийцами (III-VII вB. н. э.), Арабскому халифату (VII-XIII вв. н. э.), тюрко-монгольским династиям (XIII-XV вв. н. э.) [6].

X-XIII века нашей эры ознаменовались появлением первых самостоятельных курдских династий, среди которых были Хасанвайхиды, Марваниды, Шаддадиды, Айюбиды. В этот же период на арене истории появляется знаменитый курд - победитель крестоносцев, султан Салах-ад-Дин, покоривший Египет, Сирию, Палестину, Йемен, Центральный и Юго-Восточный Курдистан [7].

Ни одна из курдских династий в отмеченный период не смогла добиться поддержки большинства курдских племен-конфедераций, получить широкое распространение и надолго удержать завоеванные территории. Автономность курдских племен была основана на особенностях хозяйственно-экономического уклада жизни - скотоводстве, кочевье, необходимости выживать в условиях сложного горного ландшафта и трудного доступа к пастбищам. Природная среда и жизненные обстоятельства в равной степени способствовали как усилению внутриплеменной солидарности, так и обострению межплеменной конкуренции.

Геополитическое положение не позволило изжить, а, наоборот, усугубило раздробленность курдского этноса, но не подорвало его существование и развитие, а лишь способствовало проявлению его специфических черт. К важнейшей черте курдского этноса следует отнести курдское племя - социальный институт, значение и функции которого необходимо осветить подробнее.

Племя - традиционное сообщество людей, отличающееся высокой мерой интеграции, единством в понимании ценностей и разделением общих убеждений. До недавнего времени племя рассматривалось главным образом как начальная ступень развития этноса, предшествующая формированию народности и нации. Однако взгляд на курдское племя как на пережиток прошлого препятствует полноценному анализу курдского этноса. Много лет подряд в курдоведении племя рассматривалось как вид социальной организации, препятствующий завершению процессов этнической консолидации. Но тот факт, что племенная структура на протяжении многих веков, вплоть до настоящего времени, успешно функционирует в курдском обществе, заставил ученых по-новому взглянуть на ее роль.

Как пишет Е.И. Васильева, «интегративно-охранительная потенция, заложенная в племени, обеспечивала его жизнестойкость и неиссякаемую способность к регенерации. В периоды экстремальной напряженности в Курдистане, во времена военных действий и разрухи, которыми так богата история страны курдов, в горах племя оставалось единственной структурой, сохранявшей способность в доступных ей пределах контролировать ситуацию. 
Племя как специфическая форма социальной организации выступало для курдов прибежищем экономического, политического и идеологического характера. Курды едва ли смогли бы сохранить себя как этносоциальную общность, если бы в экстремальные моменты своей истории они не имели возможности уходить в свои горы, где их оплотом служили кочевье и племя.

В племени как социально-политической структуре мы имеем не более низкий уровень социального развития, а иной уровень усложненности, вернее, отсутствие усложненности» [8, с. 208].

Традиционно курдские племена состояли из нескольких подразделений, возглавляемых правящим кланом, или правящим домом. Крупное племя могло объединять несколько родов. Несмотря на высокую степень внутриплеменной солидарности и зачастую безоговорочное подчинение правящему дому, родство в племени играло важнейшую роль, а законы кровной мести могли привести к конфрликтам между подразделениями.

При разрастании подразделения до предельных размеров, когда конфликтные отношения между соплеменниками начинали носить системный характер, а в борьбу за лидерство вступали несколько равнозначных по авторитету претендентов на старшинство, подразделение дробилось на несколько частей. Этот процесс носил скорее эволюционный характер и происходил, как правило, без потрясений и на договорной основе.

Право на распределение и перераспределение власти всецело принадлежало правящему дому. Племенные лидеры изначально выдвигались или поддерживались членами племени. С течением времени из семей племенных лидеров формировались аристократические кланы, составлявшие элиту курдского общества. Племенное сообщество добровольно утверждало право правящего клана на власть. Правящий дом воспринимался членами племени как оплот и гарант стабильного существования. Утрата власти правящим домом погружала жизнь сообщества в хаос. Элитарный дом опекали, члены племени могли инициировать восстановление власти правящего клана, не дожидаясь сигнала о готовности самого правящего дома [9]. Такие факты не просто описывают особенности социального и политического уклада курдского племени, но свидетельствуют о высоком уровне внутриплеменной солидарности.

Для поддержания и укрепления власти члены правящего дома на определенном этапе конструировали себе «новую» родословную, призванную возвысить их клан в глазах соплеменников. Например, утверждалось, что корни правящей династии уходят в глубь веков и она находится в родстве с пророками [10, с. 61].

Племена подразделялись на кочевые, полукочевые и оседлые. Часто большая часть подразделений племени кочевала, лишь несколько из них были оседлыми. Кочевые и полукочевые племена передвигались в соответствии с выработанными столетиями маршрутами миграции. Право на стоянки в Курдистане сочеталось с правом на пастбища, пожалованным или присвоенным силой, и это право было нерушимым. Несмотря на вражду, разные племена могли использовать одни и те же пастбища в разные сезоны, если это было закреплено в результате межплеменной договоренности [11, с. 15]. Кочевье длилось месяцами, члены племени преодолевали расстояния в сотни километров.

Кочевой образ жизни был сопряжен со множеством трудностей и опасностей. Передвигались семьи поэтапно. Большая нагрузка ложилась на всех членов семьи - и мужчин, и женщин, и способных приносить пользу детей. Приходилось гнать большие стада животных по крутым горным склонам, узким тропам, переправляться через бурные горные реки.

Многовековой кочевой образ жизни племени сыграл значительную роль в формировании мобильной, сплоченной солидарной социальной структуры. Помимо очевидного рационального использования богатства горных пастбищ, кочевье позволяло племени в случае необходимости быстро спастись от превосходящего по силе противника, укрыться в горах, сохранить не только жизни людей, но и скот - основу хозяйственной деятельности.

Помимо того что племенная организация способствовала высокой мобильности членов племени, она также создавала условия для маневренности политической жизни курдского общества. Военно-стратегические и тактические союзы между племенами складывались быстро, иногда стихийно, если этого требовала ситуация, например для захвата новых территорий. Претендующие на формирование нового племенного сообщества подразделения, прежде чем обрести независимость от своего правящего дома, могли примкнуть к другому племени.

Таким образом, несмотря на то, что на первый взгляд может показаться, будто племенная структура курдского общества препятствовала и препятствует его этноконсолидации (отчасти это верно), пристальное изучение вопроса позволяет сделать заключение о решающем значении данного типа социальной организации для сохранения курдского этноса на протяжении многих веков.

Описанная выше борьба за территории исторического проживания курдов должна была атомизировать курдский этнос. Но хозяйственные, социальные и политические связи курдов были сохранены социальным институтом племени. Племена делились, объединялись, появлялись совершенно новые племенные объединения, однако курдский этнос сохранял жизнестойкость в условиях господства различных империй и династий. Завоеватели могли лишь отчасти 
устанавливать свои порядки. В основном это заключалось в налогообложении курдских племен. Однако стоило племени уйти в горы, оно становилось недосягаемым. Легитимно признаваемой властью всегда оставался правящий дом племени [12, с. 62].

Горный рельеф, нехватка благоприятных для земледелия территорий послужили причиной того, что доминирующей формой хозяйствования курдов многие века было отгонное скотоводство с перекочевками весной на высокогорные пастбища, зимой - в долины и ущелья. Географическая среда во многом детерминировала укрепление племенной структуры как основы социальной жизни курдского народа. Трудности выживания в условиях дикой природы способствовали непререкаемости авторитета вождя и преобладанию коллективизма над индивидуализмом, поскольку постоянная мобилизация физических и моральных сил не предоставляет времени и возможности сомневаться в лидере, а ежедневные тяжелый физический труд и достижение общего результата невозможны без высокой групповой солидарности.

Союзы племен выступали протогосударством, созданным для целей осуществления защитной и хозяйственной деятельности. Вождь племени из правящего клана сосредоточивал функции законодательной, исполнительно-административной, судебной и военной власти. Описанная выше социальная структура была детерминирована вызовами географической и исторической среды. Она в определенной мере препятствовала развитию подлинного национального самосознания, но позволила выжить курдскому народу как этносоциальной общности.

Географические условия проживания, возможно, также повлияли на тот фракт, что курдский язык подразделяется на несколько наречий. Относительно обособленное существование племен, разделяемых ландшафтными границами, а впоследствии влияние языка и культуры пришедших завоевателей явились причиной того, что курдский язык включает два основных (курманджи и сорани) и множество местных диалектов. Несмотря на разнообразие наречий, курдский - это единый язык, относящийся к группе иранских, отличающийся своими законами фонетики и особым синтаксисом [13, с. 209].

Описанные выше особенности социальной организации, хозяйственной деятельности, политических отношений в равной степени относятся к предкам курдов, проживающих на сегодняшний день в Иракском Курдистане.

Если придерживаться подхода, в рамках которого формирование этнического самосознания предшествует развитию национального самоопределения, то необходимо, с одной стороны, выделить ряд ключевых этапов в истории курдского общества, приведших к появлению Иракского Курдистана, а с другой стороны, акцентировать внимание на процессе становления национальных движений курдов, которые также неразрывно связаны с Южным Курдистаном.

Летом 1514 г. в результате столкновения турецкой и персидской армий под Чалдыраном появилась граница между Османской империей и Сефевидским государством. Несмотря на многократные попытки сместить границу, предпринимавшиеся обеими сторонами, она просуществовала несколько веков и впоследствии повлияла на формирование границ современных государств региона. Участвовавшие в Чалдыранском сражении курды в большинстве своем встали на сторону турков. Этому способствовало то, что курдские племена на протяжении нескольких лет были объектом нападения со стороны разрастающегося государства под предводительством династии Сефевидов и были настроены дать захватчикам отпор. Значимую роль также сыграл религиозный фактор: курды, как и османский султан, исповедовали суннитскую доктрину ислама, в то время как иранский шейх - шиитскую.

Большая часть территории Курдистана отошла Османской империи. Курдские земли были подразделены на административные территории - пашалыки. Проживавшие там племена получили фактически независимый статус. Правители этих земель могли чеканить монеты, в их честь читалась пятничная молитва, они не были подотчетны османскому султану и не платили ему дань. Взамен они обязались не поднимать восстания против Порты и не расширять границы принадлежащих им территорий. Формально последнее требование защищало права соседних административных территорий, однако по сути оно было призвано препятствовать централизации Курдистана. В наиболее суровых и труднодоступных землях, где осуществление военного контроля представлялось невозможным, вожди курдских племен получали право наследования и фрактически сосредоточивали всю власть в своих руках [14, p. 14].

В описываемый период XVI-XVIII вв. племена, проживающие на территории Южного Курдистана, получили специальный статус в рамках Османской империи, позволявший им избежать ассимиляции, сохранить и укрепить этническую уникальность, в отличие от курдов, проживавших на землях, которые были отнесены к Сефевидскому государству, и подвергшихся большему влиянию со стороны персов. Возможно, разная политика в отношении курдских племен определялась стадией развития государств-завоевателей. Династия Сефевидов активно объединяла иранские племена в единое государство, налаживала централизованное управление и так же была нацелена поступить с любыми другими племенами, в то время как Османская империя уже была сильно централизована и ставила иные задачи на описываемом этапе развития. Немаловажную роль в установлении особого статуса для курдов в рамках Османской империи сыграл 
Шарафр-хан Бидлиси. Курд по происхождению, приближенный османского султана, он сыграл посредническую роль между курдскими племенами и османским правителем [15, p. 27-29].

Однако необходимо помнить, что и вожди курдских племен, и османские султаны в моменты ослабления одной из сторон договора стремились установить абсолютную власть. Таких моментов в истории региона было немало. Турецко-персидские столкновения, регулярно вспыхивавшие в обозначенный исторический период вплоть до начала XIX в., позволяли крупнейшим курдским племенам и эмиратам (в случае с Южным Курдистаном племени джафов [16] и эмиратам Бабан, Соран, Бахдинан [17, с. 119]) сохранять относительную независимость, опираясь на интересы и поддержку одной из враждующих сторон.

XIX век в истории курдов, проживающих на территории Южного Курдистана, был ознаменован рядом знаковых сепаратистских выступлений против центральных властей и их наместников. Деятельность эмира Бабана Абдуррахман-паши и его сына Махмуда-паши, правление Зубейр-паши в эмирате Бахдинан, положение джафов в начале XIX в. заложили фундамент освободительных движений курдского народа. Сложившаяся социально-политическая конъюнктура, а именно удаленность от центра империй, перманентно вспыхивающие конфликты на турецкоиранской границе, большое влияние вождей курдских племен, являющихся фрактическими лидерами и легитимными властителями в глазах курдов, воспринимаемое резко негативно как посягательство на свободы и традиции курдов, давала курдам Южного Курдистана фрактическую возможность бороться за независимость и расширение своих территорий, чем они успешно пользовались. Однако создание независимого государства, хотя бы на части территории Курдистана, так и не стало реальностью.

Веками формируемая этническая идентичность курдов, основанная на общности территорий проживания, общности социального устройства на базе единых природно-географических условий жизни, общности традиций, закрепленных в особом укладе жизни и культурных образцах, способствовала развитию и укреплению этнического самосознания курдов.

Непреложность общности происхождения, длительное совместное существование, единые формы социальной жизни, присущий только курдам национальный менталитет, общность истории нашли отражение в сознании курдов. Этническая идентичность курдов Южного Курдистана была сфрормирована уже в XIX в., о чем свидетельствуют многочисленные попытки лидеров курдских княжеств объединиться на основании общих социально-экономических признаков. Однако эти объединения еще носили недолгосрочный характер, не было четкой программы дальнейших действий и сформулированной национальной идеологии. Развитое чувство принадлежности кединому этносу создало фундамент для появления и роста национального сознания и национально-освободительных движений курдов Южного Курдистана. Отдельные черты сложившихся социальных структур, такие как клановость, личные интересы элит и религиозных лидеров [18], невовлеченность рядовых курдов в коммуникационные процессы национальной агитации, препятствовали фрормированию подлинного национального сознания вплоть до начала XX в.

\section{Ссылки:}

1. Essays on the origins of Kurdish nationalism / ed. by A. Vali. Costa Mesa, 2003. P. 68.

2. Hassanpour A. Nationalism and language in Kurdistan, 1918-1985. San Francisco, 1992.

3. Минорский В.Ф. Курды. Заметки и впечатления. Петроград, 1915.

4. Sheyholislami J. Kurdish identity, discourse, and new media. N. Y., 2011.

5. A people without a country: the Kurds and Kurdistan / ed. by G. Chaliand. L., 1993.

6. Минорский В.Ф. Курды. Заметки и впечатления. С. 189-191; Sheyholislami J. Op. cit. P. 50.

7. Минорский В.Ф. Указ. соч. С. 191-201 ; Minorsky V. Studies in Caucasian history. Cambridge, 1957. P. 124-132.

8. Васильева Е.И. Курдские историографы о курдских племенах (от Шарафр-хана Бидлиси - XVI в. до Мирзы Али-Акбара Курдистани - XIX в.) // Письменные памятники Востока. 2010. № 2 (13). С. 207-230.

9. Васильева Е.И. Курдские историографы ... С. 211-212 ; История Курдистана / М.С. Лазарев, Ш.Х. Мгои, Е.И. Васильева, М.А. Гасратян, О.И. Жигалина. М., 1999.

10. История Курдистана. С. 61.

11. McDowall D. A modern history of the Kurds. N. Y., 2004.

12. История Курдистана. С. 62.

13. Минорский В.Ф. Курды - потомки мидян // Письменные памятники Востока. 2013. № 1 (18). С. 206-212.

14. A people without a country ... P. 14

15. McDowall D. Op. cit. P. 27-29.

16. Васильева Е.И. Джафы, названные типичным курдским племенем классического типа // Письменные памятники Востока. 2010. № 1 (12). С. 93-102.

17. История Курдистана. С. 119.

18. Джалилов О.Дж. Исторические песни курдов. СПб., 2003. С. 161-232 ; Шараф-хан ибн Шамсаддин Бидлиси. Шарафнаме. Т. 1 / пер. Е.И. Васильевой. М., 1967. С. 85. 


\section{References}

Chaliand, G 1993, A people without a country: the Kurds and Kurdistan, London.

Hassanpour, A 1992, Nationalism and language in Kurdistan, 1918-1985, San Francisco.

Jalilov, OJ 2003, The Kurdish historical songs, St.-Petersburg, pp. 161-232, (in Russian).

Lazarev, MS, Mgoi, ShKh, Vasilyeva, El, Gasratyan, MA \& Zhigalina, OI 1999, The history of Kurdistan, Moscow, (in Russian).

McDowall, D 2004, A modern history of the Kurds, New York.

Minorsky, VF 1915, The Kurds. Notes and impressions, Petrograd, (in Russian).

Minorsky, V 1957, Studies in Caucasian history, Cambridge, pp. 124-132.

Minorsky, VF 2013, 'The Kurds are the descendants of Medes', Pis'mennyye pamyatniki Vostoka, no. 1 (18), pp. 206-212, (in Russian).

Sharaf Khan Bidlisi \& Vasilyeva, El (transl.) 1967, Sharafnama, vol. 1, p. 85, (in Russian).

Sheyholislami, J 2011, Kurdish identity, discourse, and new media, New York, https://doi.org/10.1057/9780230119307.

Vali, A (ed.) 2003, Essays on the origins of Kurdish nationalism, Costa Mesa, p. 68.

Vasilyeva, El 2010a, 'Jaffa people are considered to be a typical Kurdish tribe of the classical type', Pis'mennyye pamyatniki Vostoka, no. 1 (12), pp. 93-102, (in Russian).

Vasilyeva, El 2010b, 'The Kurdish historiographers about the Kurdish tribes (from Sharaf Khan Bidlisi of the 16th century to Mirza Ali Akbar Kurdistani of the 19th century)', Pis'mennyye pamyatniki Vostoka, no. 2 (13), pp. 207-230, (in Russian). 